\title{
Cutaneous larva migrans : a neglected disease and possible association with the use of long socks.
}

\begin{abstract}
Cutaneous larva migrans is a common parasitic skin disease that can be easily prevented by wearing 'protective' footwear. However, this has been under-emphasized in terms of what constitutes the protective footwear. Even though the disease resolves spontaneously, the significant duration of the disease along with severity of pruritus make treatment unavoidable. Here, we present a very long-standing creeping eruption, which puzzled many attending clinicians handling the case, and the possibility of long socks as a causal effect on the development of cutaneous larva migrans infection.
\end{abstract}

Keyword: Cutaneous larva migrans; Creeping eruption; Parasitic skin disease; Protective footwear; Socks; Malaysia. 